\title{
The Development of the New Type Universal Collective Survival Craft with Unmanned Control Function for Evacuation of Personnel in Emergency Situations of Natural and Technogenic Character on the Arctic Shelf
}

\author{
I.A. Vasilyev, R.A. Dorofeev, J.V. Korushova, A.A. Koshurina \\ and M.S. Krasheninnikov
}

\begin{abstract}
The article presents the concept and the process of development of the new type universal collective survival craft. The article shows the arrangement and the interior of the vehicle and describes solutions for the main systems - chassis, life support systems, control systems, and auto piloting, showing decisions in the passenger compartment. In addition, authors describe the development process included in strength calculations of technical solutions. In conclusion, the article gives a conclusion on possible areas of use of the developed solutions.
\end{abstract}

Keywords Rotor-screw vehicles $\cdot$ Arctic $\cdot$ Rescue operations $\cdot$ Strength calculations Autopilot system computer vision $\cdot$ Robotics $\cdot$ Life boat $\cdot$ All-terrain vehicles

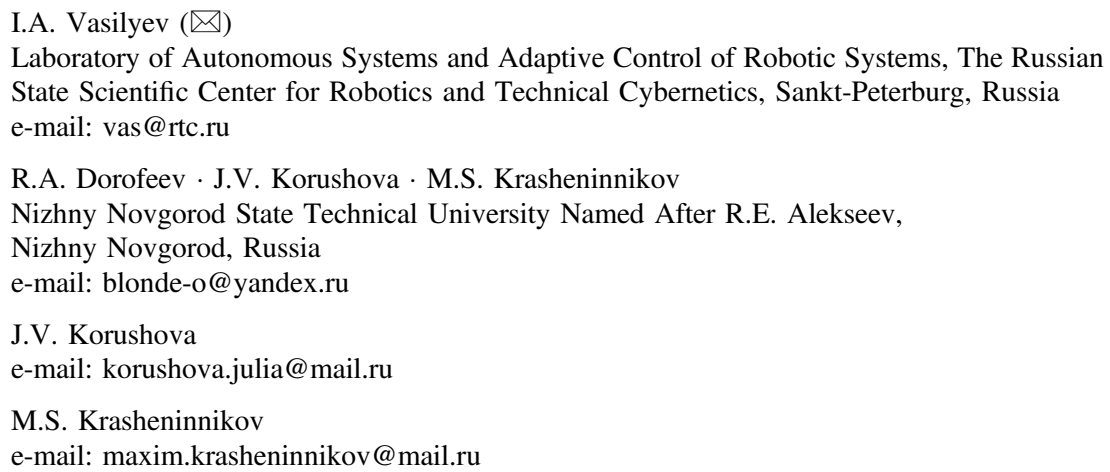


The Arctic is a special region, which in addition to the wealth of natural resources, characterized by difficult environment conditions: prolonged low temperatures, strong erosion effects of seawater, storms, strong gusty wind, poor visibility conditions, and others. The task of the Arctic region development is complicated by considerable remoteness from the nearest human habitat areas and a low level of infrastructure.

The rapid development of the Arctic region is an important issue for improving economic potential of Russia. Currently, the development of the Arctic region is associated with the development of oil and gas fields of the continental shelf of North Sea (Barents; Pechora and Okhotsk). The problem of development of a transport net has the highest priority for the region. The special role in this process is given to safety. The transport must perform complex functional tasks and conform to highest standards of reliability and safety.

Statistical analysis of accidents on offshore platforms, for the period from 1965 to 2016, confirms the ineffectiveness of conventional rescue facilities in the northern territories. The main restrictions are as follows:

- air rescue equipment (helicopters and small aircrafts) is limited by poor flight conditions, which are typical for the Arctic region;

- rescue equipments such as rafts and lifeboats are not able to move inter broken ice (about 9 months per year);

- submarines, in addition to the very high prices, have difficulties with mounting under the platforms (which have an extensive network of pipes under water surface). Also, it requires a large number of units of submarines for rescue of all personnel platforms (up to 250-350 persons).

The growth of victims number of accidents on the platforms is connected with the increase in jobs in the northern seas, in the absence of an effective rescue equipment. An average of $67 \%$ of staff dies at the time of the accident in the northern seas. For example, on December 18, 2011, 53 personnel members out of 67 died on Sakhalin Island during transportation of the drilling platform "Kola".

Scientists and engineers from Russia, Norway, Canada, and the United States are trying to solve the problem of the efficient rescue operations in the Arctic. The solution of the problem consists in the development of the new type of rescue equipment, which is the amphibious all-terrain vehicle. According to government estimates, 1000 units of rescue equipment may be required by 2020 year. This amount constitutes $7-10 \%$ of the total number of vehicles required for the Far North and the Arctic.

Currently, several all-terrain vehicles (wheeled, tracked, rotary-screw) are proposed for the task. The list includes hovercraft Arctica, all-terrain vehicles ARKTOS, Vityaz', A.R.C., and others. However, one of the key problems is the choice of construction materials and protection methods of icing and extreme overheating due to the vehicle passage through a burning oil spill (which can happen in accidents). Regulatory documents (SOLAS 74; GOST R 52638-2006; 
Rules of the Russian Maritime Register of Shipping and the International Life-Saving Appliance Code) contain strict requirements of fire protection for rescue vehicles. The design of the rescue vehicle should allow being in an area of burning oil at least for $8 \mathrm{~min}$. The vehicle immediately returns to the zone of low temperatures after overcoming of the area of burning oil. The temperature changing can cause high thermal stresses, leading to damaging of the material of the hull.

Currently, the team of the scientific and educational center "Transport" of Nizhny Novgorod State Technical University has developed the first experimental model of the universal rescue vehicle. This prototype is intended for testing of technical solutions for reduction of human casualties in accidents on offshore oil platforms. The rotary-screw mover was taken as a base for the rescue vehicles concept Figs. 1 and 2.

Particular attention was paid to the design of functional equipment and ergonomics. The psychological aspect has a great importance, because a person in a

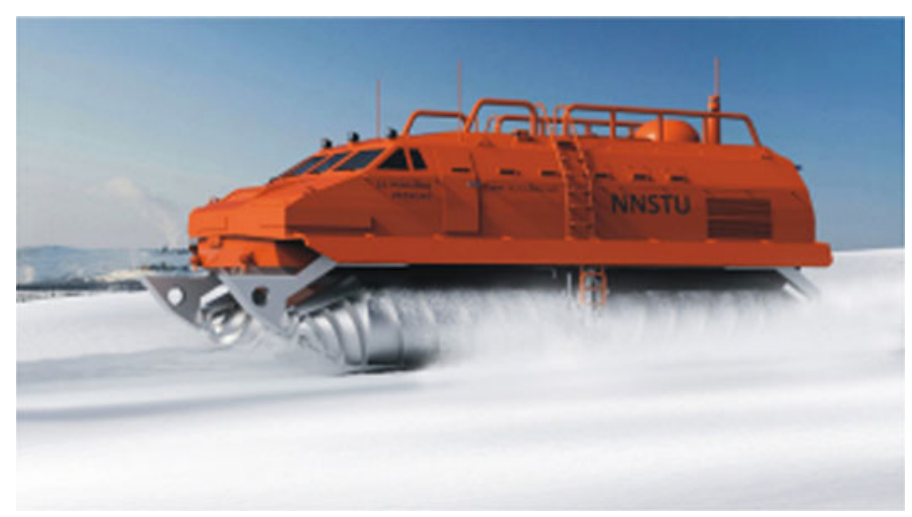

Fig. 1 The visualization of the universal rescue vehicle appearance

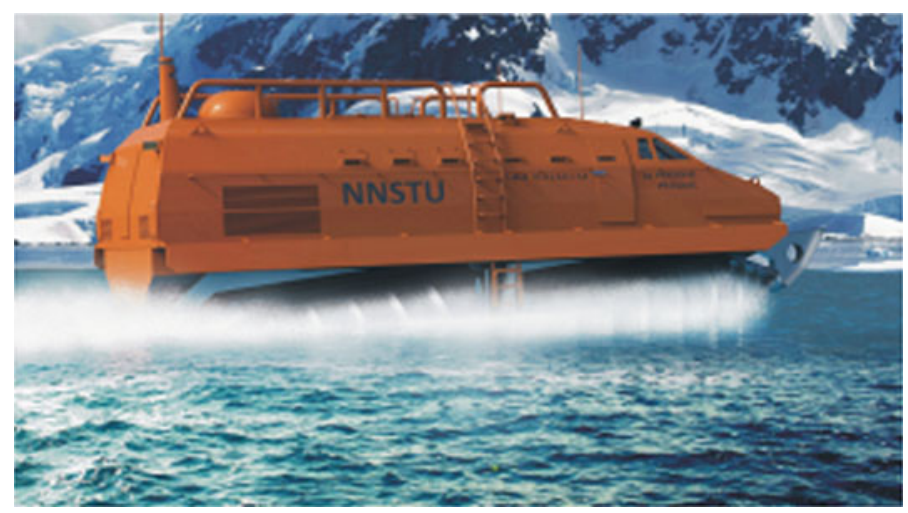

Fig. 2 The universal rescue vehicle moving on water 
stressful situation should make quick and right decisions. That was the main reason for the development of intuitive and friendly inner space of the vehicle. The basic sample of the rescue vehicle would belong to the light class rescue vehicles and be designed for 14 people and 2 crew persons, but also it can accommodate six more people if necessary. The protection of people inside the vehicle from overloads appearing during driving on difficult terrain (icefields, wormwood, movement in broken ice, and others) is the essential task. That is why every person in the vehicle is located on an individual seat (Fig. 3) with protection from mechanical vibrations. The seats have the possibility of conversion to a sleeping berth for a case of long rescue operation. Thanks to individually adjustable backrest, footrest, headrest, and lumbar support, the chair can be customized for each person.

The dimensions and the amount of the seats make a decisive contribution to the forming of the passenger compartment, the layout, and appearance of all survival crafts (Figs. 4 and 5).

The vehicle will have the following dimensions: length $-11.5 \mathrm{~m}$, width $-5 \mathrm{~m}$, and height $-4.5 \mathrm{~m}$. Total weight is 13 tons, of which up to 3 tons is load capacity of the vehicle. The layout of the universal rescue vehicle is shown in Fig. 6.

In accordance with the above scheme of the vehicle, the pilot cabin is located in the nose, then the passenger cabin, bathroom and utility room, and the room for the power plant. Other technical systems are located under the passenger compartment floor.

The universal rescue vehicle is developed for autonomous work for 3 days. The maintenance of comfortable conditions in the vehicle during the operation is achieved through the following sections: 1. the compartment-containing toilet, shower, sink, and cabinet for clothes (Fig. 7); 2. the room with basic supplies of food and medicine, as well as a mobile kitchen for cooking or heating food (Fig. 8).

Fig. 3 The individual seats

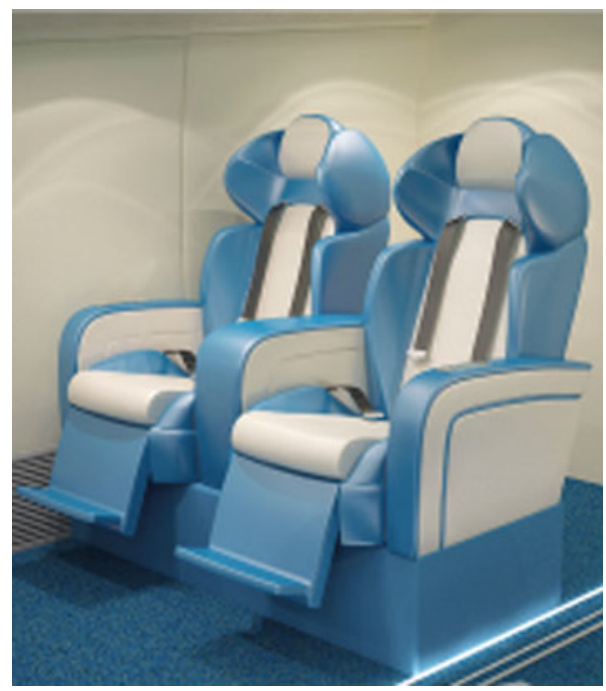




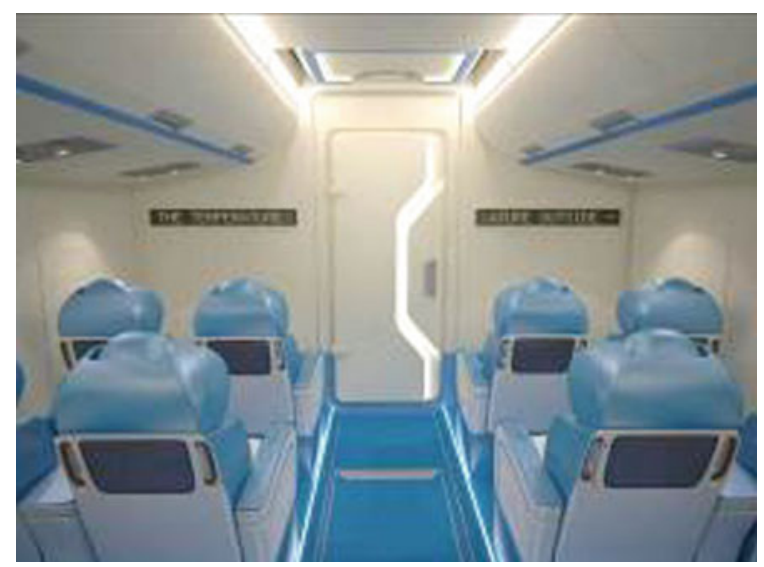

Fig. 4 The passenger compartment (the front view)

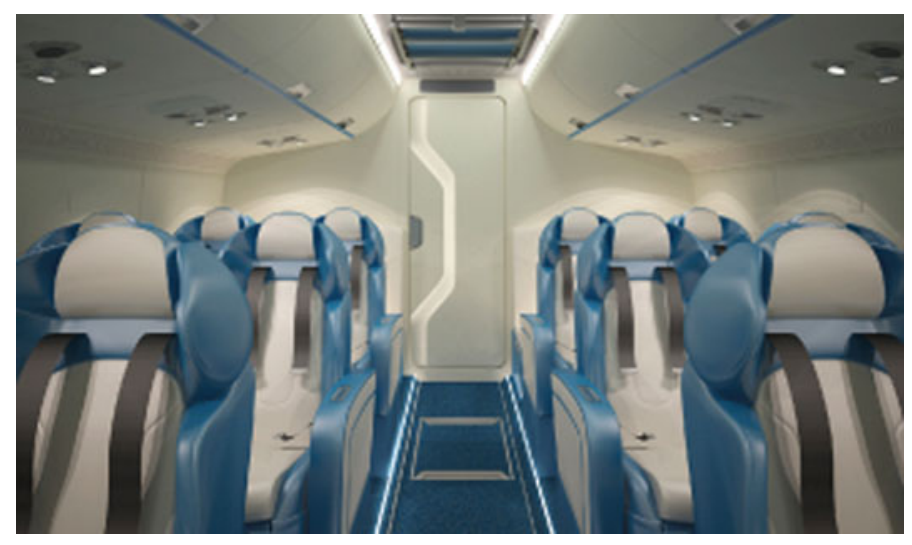

Fig. 5 The passenger compartment (the rear view)

The vehicle is equipped with life support systems to protect from the major risk factors associated with the possibility of overcoming the burning oil stains, long stay in low-temperature conditions at high humidity, and others. The main systems are as follows: firefighting, autonomous air supply, de-icing, climate control, autonomous power supply, sound insulation, vibration isolation, and lighting. The most important systems are duplicated.

The issue of permeability and high driving quality is of paramount importance for the Universal rescue vehicle. The movement on difficult terrain (ice fields, broken ice, hummocks, and others.) sets the task of creating a unique multi-function universal chassis system. This system was developed in the course of the project. The vehicle has a suspension system, which adapts its own characteristics to the 

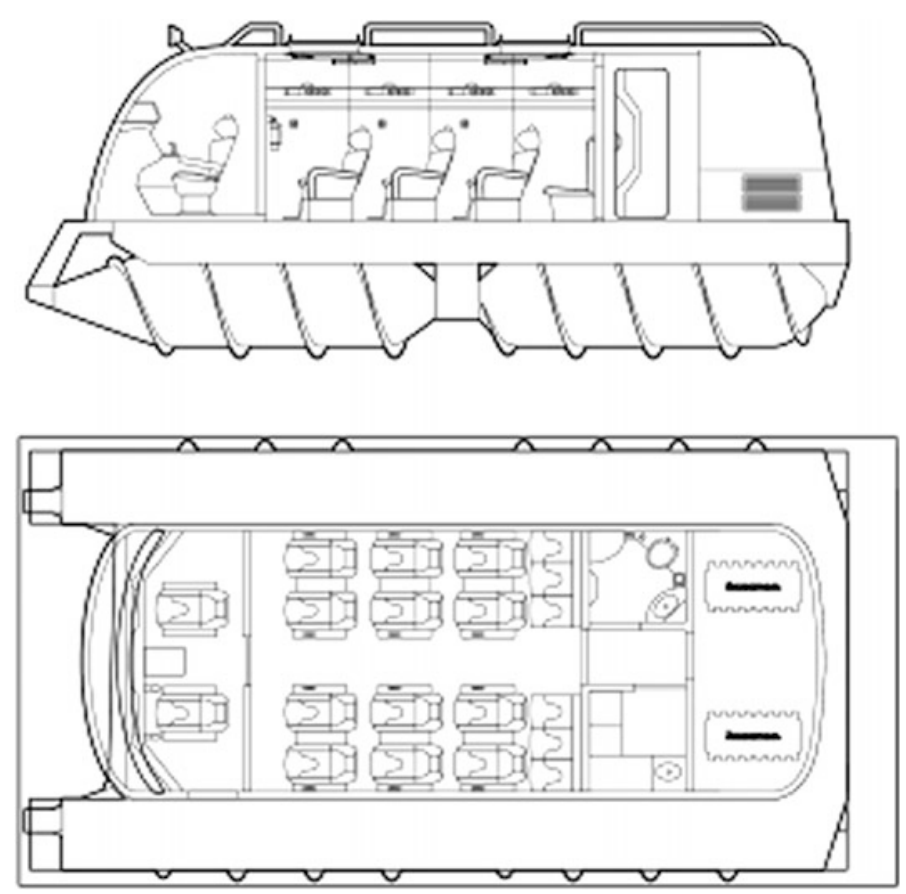

Fig. 6 The layout of the universal rescue vehicle

Fig. 7 The restroom

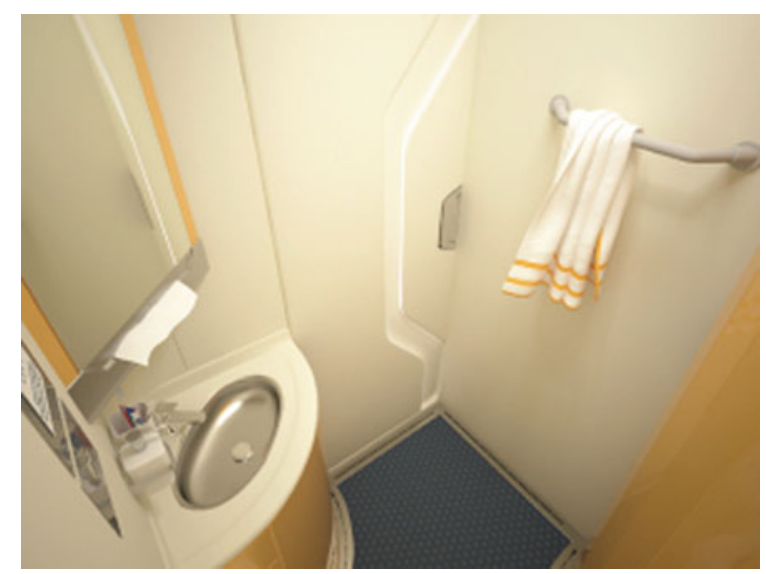

type of support base. In accordance with the data of the work [2, p. 328] the vehicle must have the ability to climb from water to ice barrier at the height of $2 \mathrm{~m}$. For this task, the chassis system has the opportunity to change the position of basic elements [1, p. 1266]. The significant suspension travel can significantly reduce the dynamic loads on the passengers and crew. 
Fig. 8 The utility area

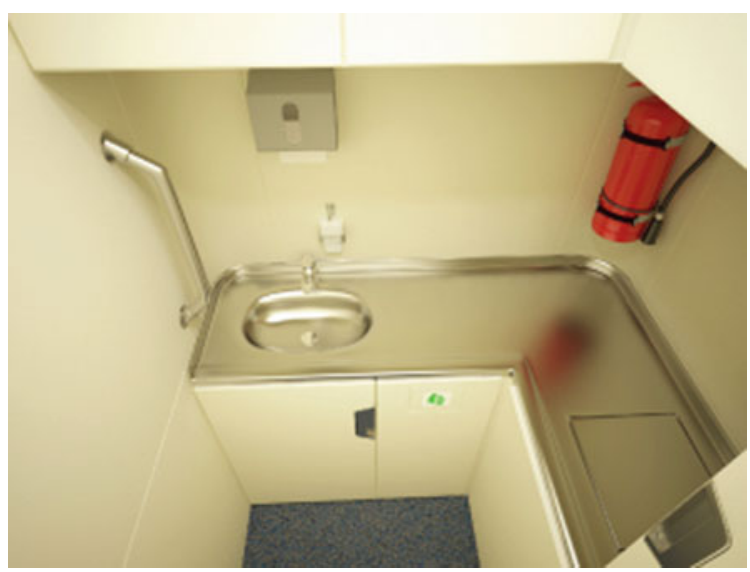

Rotary-screw propeller will experience cyclic loads. One of the characteristic modes of the load is the process of the entrance from water to ice. Performed strength calculation has confirmed the correctness of design decisions [2, p. 5606]. The stress level does not exceed $250 \mathrm{MPa}$. It corresponds to the zone of elastic deformation for the mover's material. Figure 9 shows the stress-strain state of the rotary-screw mover during the entrance from water to ice.

Arctic operating conditions set special requirements to structural materials for engineering. The choice of materials is of particular importance for the Arctic rescue vehicle. Materials must conform to difficult climatic conditions and must not allow degradation of properties in significant temperature ranges. The combination of all of the desired characteristics is made possible by a combination of modern materials. The use of sandwich panels for the construction of the hull allows a low specific gravity to achieve the required performance for stiffness and strength of the hull.

The autopilot system was created for the pilot workload reduction. The system provides quick deciding in a disasters situation, as well as in a complex and changing terrain. The system provides the following kinds of control: simple, alert, tracking (semi-automatic), adaptive, and navigation by GPS ("movement along a predetermined path"). The system is based on a vision system that combines sensors with different physical natures: video cameras, range finders, radar, sonar, and others. Complex vision system provides spatial orientation in difficult visibility conditions.

The composition of the technical equipment of computer vision system is a hardware-software complex "improved vision" (Enhanced Vision Systems, EVS). EVS system-generated random image information appears below the pilot in real time on the multi-function remote control as a panoramic image of the situation behind the cabin. The autopilot system and the supervision system were carried out jointly with the Russian State Scientific Center for Robotics and Technical Cybernetics (RTC). 
(a)

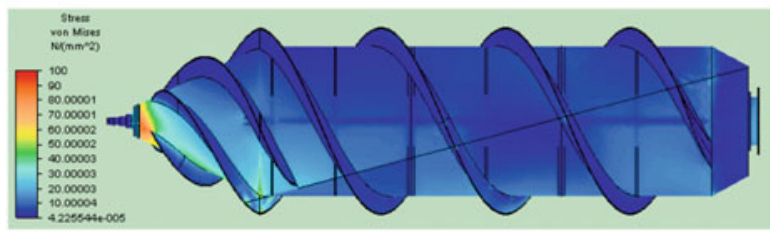

(b)

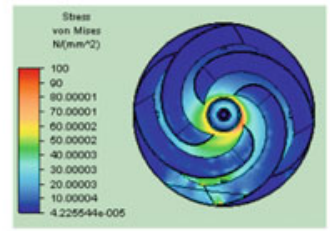

(c)

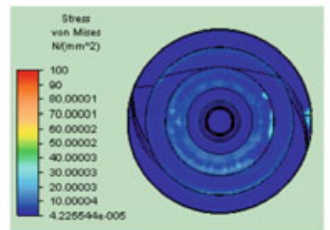

(d)

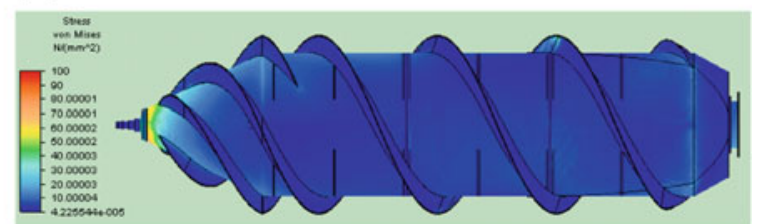

(e)

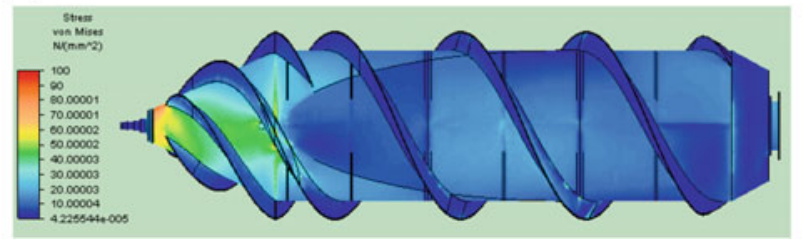

Fig. 9 The strain-stress (the scale $1 \times 1$ ): a left; $\mathbf{b}$ front; $\mathbf{c}$ rear; $\mathbf{d}$ top; e bottom

Currently, the experimental model of the universal rescue vehicle was built (Fig. 10). The model has the following characteristics: length $5.5 \mathrm{~m}$, width $2.6 \mathrm{~m}$, height $2.4 \mathrm{~m}$, Curb weight/gross $3500 / 4500 \mathrm{~kg}$, diesel engine $186 \mathrm{~kW}$, hydraulic transmission, and the maximum speed in water $12 \mathrm{~km} / \mathrm{h}$ and in the snow $23 \mathrm{~km} / \mathrm{h}$.

The sample is equipped with the original integrated onboard control system with the function of the autopilot, including navigation systems and computer vision. At the end of 2016, complex tests of the vehicle are planned. The main goal of the tests is the estimation of driving performance on different surfaces, including open water.
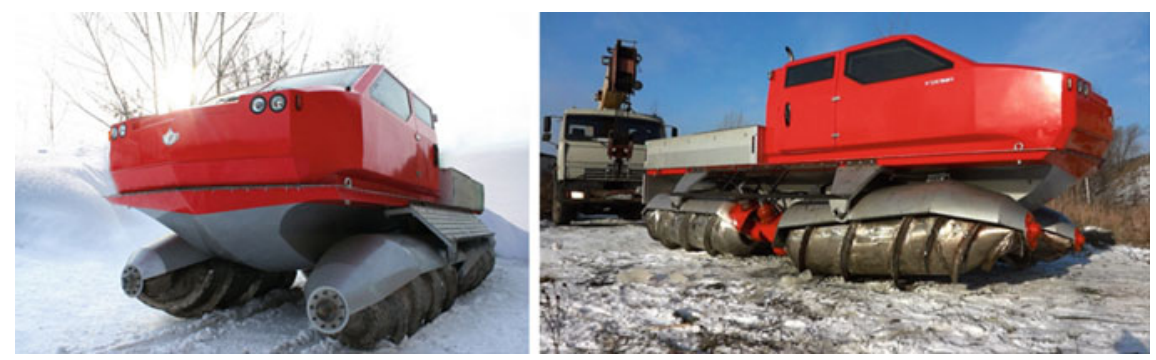

Fig. 10 The experimental model of the universal rescue vehicle 


\section{Conclusions}

The level of the developed technical solutions allows their applying in other areas of potential use of rotary-screw vehicles. It was achieved, thanks to the complexity of the assigned task and the depth of study. The universal multi-function chassis might be efficiently used in the following areas: rescuing people, securing the Northern Sea Route, environmental monitoring, execution of works in shallow water, elimination of oil spills, pipeline construction, and geological prospecting. Patents protect results of intellectual activities of the project team.

Acknowledgments Research is carried out (conducted) with the financial support of the state represented by the Ministry of Education and Science of the Russian Federation. Agreement (contract) no. 14.577.21.0105, September 16, 2014. Unique project Identifier: RFMEFI57714X0105.

\section{References}

1. Koshurina, A.A., Krasheninnikov, M.S., Dorofeev, R.A.: Strength calculation and analysis of equalizer beam embodiments for the operated equalizing beam suspension of the Universal rotor-screw rescue vehicle for the arctic. Procedia Eng. 150, 1263-1269 (2016)

2. Skutin, A.A., Naumov, A.K., Kubyshkin, N.V.: Evaluation of morphometric characteristics of the icebergs in the Barents Sea with the full data for modeling the drift // Sbornik trudov 10-j Mezhdunarodnoj konferencii po osvoeniju resursov nefti i gaza Rossijskoj Arktiki i kontinental'nogo shel'fa stran SNG "RAO/CIS Offshore-2011", SPB (2011)

3. Koshurina, A., Blokhin, A., Krasheninnikov, M., Dorofeev, R.: The strain-stress state of the rotor during entrance of the rotor-screw vehicle from water to ice. ARPN J. Eng. Appl. Sci. 9, 5603-5607 (2016)

Open Access This chapter is licensed under the terms of the Creative Commons Attribution 4.0 International License (http://creativecommons.org/licenses/by/4.0/), which permits use, sharing, adaptation, distribution and reproduction in any medium or format, as long as you give appropriate credit to the original author(s) and the source, provide a link to the Creative Commons license and indicate if changes were made.

The images or other third party material in this chapter are included in the chapter's Creative Commons license, unless indicated otherwise in a credit line to the material. If material is not included in the chapter's Creative Commons license and your intended use is not permitted by statutory regulation or exceeds the permitted use, you will need to obtain permission directly from the copyright holder. 